\title{
Health status has improved more in women than in men with rheumatoid arthritis from 1994 to 2009: results from the Oslo rheumatoid arthritis register
}

\author{
C Austad, ${ }^{1}$ T K Kvien, ${ }^{1}$ I C Olsen, ${ }^{1}$ T Uhlig ${ }^{1,2}$
}

\section{Handling editor Hans WJ Bijlsma}

- Additional material is published online only. To view please visit the journal online (http://dx.doi.org/10.1136/ annrheumdis-2013-204014)

1 Department of Rheumatology, Diakonhjemmet Hospital, Oslo, Norway

${ }^{2}$ Department of Rheumatology, National Resource Center for Rehabilitation in

Rheumatology, Diakonhjemmet Hospital, Oslo, Norway

\section{Correspondence to}

Dr Cathrine Austad, Department of Rheumatology, Diakonhjemmet Hospital, P.b. 23 Vinderen, Oslo 0319, Norway; cathrine@austad.us

Received 25 May 2013 Revised 12 September 2013 Accepted 29 September 2013 Published Online First 14 October 2013

\section{CrossMark}

To cite: Austad C,

Kvien TK, Olsen IC, et al.

Ann Rheum Dis

2015:74:148-155.

\section{ABSTRACT}

Objective To examine changes in patient reported outcome measures (PROs) over 15 years in a representative population of patients with rheumatoid arthritis (RA), with a particular focus on gender differences.

Patients and methods Patients in the Oslo RA register filled in questionnaires including the Modified Health Assessment Questionnaire (MHAQ), the Short-Form 36 (SF-36) with physical (PCS) and mental component summaries and derived utility (SF-6D), visual analogue scales (VAS) for pain, patient global assessment of disease (PtGA) and fatigue, and checklists of medication commonly used in the treatment of RA. Data were collected at five time points during a 15-year period from 1994. Mixed model analyses were used to analyse longitudinal changes in PROs from 1994 to 1996, 2001, 2004 and 2009.

Results Data were available from 829-1025 RA patients at each time point. PROs were statistically significantly improved from 1994 to 2009 (MHAQ, SF-36 PCS, SF-6D, pain VAS, PtGA VAS and fatigue VAS; all $p<0.001)$, and also with clinically important improvement. Men reported significantly better health status than women in 1994, but women improved significantly more than men over 15 years with a reduction of the gender gap in 2009. Antirheumatic medication was increasingly used over 15 years with no gender differences.

Conclusions RA patients reported statistically significantly improved health status for most PROs from 1994 to 2009. Women improved most, and although they still reported higher disease impact than men, the gender differences were small at the final data collection in 2009.

Rheumatoid arthritis (RA) is a chronic and disabling disease affecting women approximately three times more often than men. ${ }^{1}{ }^{2}$ Gender differences in patient reported outcomes (PROs) for disease activity and functional capacity and treatment responses have been reported. ${ }^{3-5}$ Women acquire $\mathrm{RA}$ at a younger age and may report poorer health status than men despite similar medical treatment and level of joint damage. ${ }^{3}{ }^{6-9}$ Further, women may respond poorer to treatment with synthetic and biological disease modifying antirheumatic drugs (sDMARDs and bDMARDs), and one study found women more likely to receive joint arthroplasties than men despite similar imaging findings. ${ }^{6}{ }^{10}$ However, results are inconsistent as some studies did not identify gender differences in disease pattern or severity after correcting for disease duration. ${ }^{6} 10$
Physical function is reduced in RA, ${ }^{11-13}$ deteriorates with increasing age for both RA and non-RA patients, ${ }^{14}$ and is clearly worse in RA patients than non-RA controls. ${ }^{11}$ During the 1990s and 2000s treatment strategies for RA changed towards earlier and more aggressive treatment with targeted and effective medications, ${ }^{15}{ }^{16}$ leading to less impact of disease with improved physical function and health status. ${ }^{1718}$ Long term follow-up of a representative RA population in cross-sectional assessments of physical function demonstrated improving health status over 10 years. ${ }^{19}$ Such trends need to be followed as advanced therapies become more accessible to RA patients, and it is unknown whether these improvements differ across genders. The objective of this study was to examine changes in health over 15 years in a representative RA population, and in particular examine how health status developed in women versus men.

\section{PATIENTS AND METHODS}

\section{Study population}

Patients with RA in Oslo have been included in the Oslo RA register (ORAR) since 1994, and ORAR is estimated to be $85 \%$ complete for patients aged 20-79 years. $^{2} 20$ ORAR is a large, representative and community based register. ${ }^{20}$ Annual updates were performed by checking hospital records for new RA patients fulfilling the 1987 American College of Rheumatology (ACR) criteria, ${ }^{21}$ and for patients who moved out of the area or died. There are no exclusion criteria based on disease duration, disease activity or use of medication, thus the study population represents the RA population seen in clinical practice. Data were collected at five time points from 1994 to 2009, providing an opportunity to study changes in health status during a period with major improvement in treatment strategies and access to new therapies. Thus, the changes in PROs in this study may indicate whether the improved treatment and investment in management of RA patients is also reflected in improved health status and utility measures. The present study includes all patients in the ORAR aged 20-79 years responding to the questionnaire survey at least once in 1994, 1996, 2001, 2004 or 2009.

\section{Data collection and outcome measures}

Repeated cross-sectional data collection was performed by mailed questionnaires to living patients in 1994, 1996, 2001, 2004 and 2009. A core set of measures was included in all surveys: Modified 
Health Assessment Questionnaire (MHAQ), ${ }^{22}$ Short-Form 36 questionnaire (SF-36), ${ }^{23}{ }^{24} 100 \mathrm{~mm}$ Visual Analogue Scales (VAS) for pain, fatigue and patient global assessment of disease (PtGA), and checklists for use of medication and co-morbidities. The patients also reported years of education. Information on age, gender, disease duration and seropositivity was obtained from the ORAR database.

The MHAQ is a shortened version of the Health Assessment Questionnaire (HAQ), with one question from each of the eight categories of activities of daily living (dressing and grooming, arising, eating, walking, hygiene, reach, grip and 'common daily activities'). MHAQ measures the ability to perform daily activities, score $0-3(0=$ without any difficulty, $3=$ unable to do so). The HAQ has been validated in a number of languages including Swedish, which is very similar to Norwegian. ${ }^{25}$ SF-36 is a generic questionnaire measuring eight health dimensions (physical and social functioning, role-physical, bodily pain, general health, vitality, role-emotional and mental health), score 0-100 where $0=$ worst possible health state and $100=$ perfect health. Mental (MCS) and physical (PCS) component summary scores were calculated from SF-36, scale 0-100. Utility (SF-6D) was derived from SF-36, ${ }^{26}$ scale $0-1$; a living person will obtain a score between $\geq 0.29$ and 1.00 (1.00 denotes perfect health). ${ }^{27}$ On the $100 \mathrm{~mm}$ VAS scales for pain, fatigue and PtGA, 0 reflects no problem/symptom and 100 the worst possible state.

Current use of medication was recorded using alphabetical checklists for medications available in the treatment for RA (ie, glucocorticosteroids, sDMARDs and bDMARDs). Co-morbidity was recorded as absent or present ( $\geq 1$ co-morbidity) from a checklist used in the Arthritis Impact Measurement Scales 2 (AIMS2). ${ }^{28}$

Smoking was recorded as never, previous and current (including number of cigarettes per day). Age was recorded in years when the questionnaire was completed and disease onset as the year when the patient fulfilled the 1987 ACR classification criteria. ${ }^{21}$ Disease onset was based on cumulative data obtained retrospectively from the patient history as proposed by Raza et al. ${ }^{29}$ Disease duration was recorded as year of data collection minus year of disease onset. Patients were classified as seropositive if they ever had a positive rheumatoid factor test and/or anti-cyclic citrullinated peptides antibodies exceeding the normal limits based on routine laboratory testing at the time of the test. Patients who were seronegative at inclusion were not routinely rechecked. Education level was recorded in years (range 7-17 years).

\section{Statistical analysis}

SPSS V.20 was used for the analyses. Descriptive statistics present continuous variables as means with 95\% CIs and categorical variables as counts or proportions. As a conservative measure, non-overlapping 95\% CIs and two-tailed $\mathrm{p}<0.05$ were regarded as statistically significant. To test for group differences we used the two-sample independent t test for continuous variables and the $\chi^{2}$ test for proportions. Longitudinal change was examined using a mixed model approach with random intercept and Bonferroni correction to adjust for multiple testing. Using 1994 as reference year, we performed analyses for the patient population overall (adjusted for age, gender and disease duration) and by gender (adjusted for age and disease duration).

\section{RESULTS}

\section{Patient demographics}

Important patient characteristics for all time points of data collection are presented in table 1 . The respondent rates (responding/invited) were $70.8 \%(931 / 1315)$ in $1994,74.5 \%$ $(1025 / 1375)$ in $1996,58.5 \%(829 / 1411)$ in $2001,62.9 \%(914 /$ $1454)$ in 2004 and $59.7 \%(986 / 1651)$ in 2009. Respondents and non-respondents were similar for age, gender distribution and disease duration at all time points (see online supplementary table S1). The number of patients who responded once to five times were as follows: once, $\mathrm{n}=845$ ( $74.8 \%$ women); twice, $\mathrm{n}=629$ (77.9\% women); three times, $\mathrm{n}=336$ (75.0\% women); four times, $\mathrm{n}=206$ (78.6\% women); and five times (ie, to all surveys), $n=150$ ( $82 \%$ women). Respondents had similar age, gender distribution and disease duration throughout the 15 -year study period with overlapping 95\% CIs. Women and men responding to all five surveys were of similar age (64.0, SD 10.1 years vs 64.5 , SD 10.3 years, $p=0.83$.). Patients responding for the first time to the consecutive surveys after 1994 were mainly newly included in ORAR with an approximately 3:1 female:male ratio.

From 1994 to 2009 the years of education gradually increased, there was a trend towards fewer patients with co-morbidity and the proportion of seropositive patients increased. The female:male ratio was approximately 3:1 at all examination points. Women had a longer disease duration than men on most examination points. There were no statistically significant gender differences at any examination point for age, education or seropositivity. Reporting of co-morbidities was similar between genders, with no statistically significant differences at all but one (2004) time points. A total of $83(38.6 \%)$ men and $207(28.9 \%)$ women smoked in $1994(\mathrm{p}=0.01$ for gender difference) and these numbers were reduced to 53 (23.2\%) men and 170 (22.4\%) women in $2009(\mathrm{p}=0.74$ for gender difference).

Self-reported use of antirheumatic medication is presented in table 2. The proportion of patients using glucocorticosteroids remained stable through the first 10 years but was decreased in 2009. The use of sDMARDs and bDMARDs increased towards 2009.

There was no gender difference in use of glucocorticosteroids, sDMARDs or bDMARDs at any examination point (all $\mathrm{p}>0.05$ ), and the trends of increasing use of sDMARDs and bDMARDs and less use of glucocorticosteroids in 2009 was seen for both genders. In 2009, 509/587 (86.7\%) patients using sDMARDs used methotrexate, with no statistically significant gender difference (387 (50.9\%) women vs 122 (53.7\%) men, $\mathrm{p}=0.45$ ).

\section{Disease related variables over time}

Mean values with 95\% CIs for MHAQ, SF-36 PCS, VAS PtGA, VAS pain, VAS fatigue, SF-6D and SF-36 MCS from 1994-2009 are presented in table 3. For all PROs, except SF-36 MCS, the overall scores were improved in 2009 compared to 1994 (nonoverlapping 95\% CIs).

Statistically significant cross-sectional gender differences for MHAQ, SF-36 PCS, VAS PtGA, VAS pain, VAS fatigue and SF-6D were observed in 1994 and 1996 (all $\mathrm{p} \leq 0.01$ and with non-overlapping 95\% CIs). From 1994 to 2009 women improved more than men and the gender gaps were reduced for all PROs. In 2009 the 95\% CIs for men and women overlapped for all PROs (table 3 ).

These findings were further explored for change over time by mixed model analyses. Results are presented for all patients in figure 1 and separate for men and women in figure 2. The $\mathrm{p}$ values in figures 1 and 2 represent level of significance for the changes from 1994 to the indicated time points. 
Table 1 Demographic data and disease related characteristics of patients in the Oslo rheumatoid arthritis register 1994-2009

\begin{tabular}{|c|c|c|c|c|c|}
\hline & 1994 & 1996 & 2001 & 2004 & 2009 \\
\hline \multicolumn{6}{|c|}{ Respondents, n (\%) } \\
\hline Overall & 931 (70.8) & $1025(74.5)$ & $829(58.5)$ & $914(62.9)$ & $986(59.7)$ \\
\hline Women & $716(76.9)$ & $797(77.8)$ & $639(77.1)$ & $721(78.9)$ & $758(76.9)$ \\
\hline \multicolumn{6}{|c|}{ Age (years), mean $(95 \% \mathrm{Cl})$} \\
\hline Overall & 60.6 (59.7 to 61.5$)$ & $60.8(60.0$ to 61.7$)$ & 60.8 (59.9 to 61.7$)$ & 58.7 (57.8 to 59.6$)$ & 59.4 (58.6 to 60.2$)$ \\
\hline Women & 60.5 (59.4 to 61.5$)$ & 60.4 (59.5 to 61.4) & $60.4(59.4$ to 61.4$)$ & 58.6 (57.6 to 59.6$)$ & 59.5 (58.6 to 60.5$)$ \\
\hline Men & 60.9 (59.1 to 62.8$)$ & 62.2 (60.4 to 63.9$)$ & $62.0(60.1$ to 63.9$)$ & 59.3 (57.5 to 61.1$)$ & 59.0 (57.5 to 60.6$)$ \\
\hline $\mathrm{p}$ Value & 0.68 & 0.10 & 0.14 & 0.52 & 0.60 \\
\hline \multicolumn{6}{|c|}{ Disease duration (years) } \\
\hline Overall & 12.6 (11.9 to 13.3$)$ & 13.8 (13.1 to 14.4$)$ & 13.9 (13.2 to 14.6$)$ & 13.6 (12.9 to 14.2$)$ & 13.7 (13.0 to 14.3$)$ \\
\hline Women & 13.2 (12.4 to 14.1$)$ & $14.3(13.5$ to 15.1$)$ & 14.3 (13.5 to 15.2$)$ & $13.8(13.0$ to 14.6$)$ & 14.1 (13.3 to 14.9$)$ \\
\hline Men & 10.5 (9.2 to 11.8$)$ & 11.9 (10.7 to 13.2$)$ & 12.5 (11.1 to 13.9$)$ & $12.6(11.2$ to 14.0$)$ & $12.3(11.0$ to 13.6$)$ \\
\hline p Value & 0.001 & 0.001 & 0.03 & 0.15 & 0.02 \\
\hline \multicolumn{6}{|c|}{ Education (years) } \\
\hline Overall & 11.5 (11.3 to 11.7$)$ & $11.3(11.1$ to 11.5$)$ & 11.9 (11.7 to 12.1$)$ & $12.4(12.2$ to 12.6$)$ & $12.8(12.6$ to 13.0$)$ \\
\hline Women & 11.4 (11.2 to 11.7$)$ & 11.2 (11.0 to 11.5$)$ & $11.8(11.6$ to 12.1$)$ & $12.3(12.1$ to 12.6$)$ & $12.9(12.6$ to 13.1$)$ \\
\hline Men & 11.6 (11.1 to 12.1$)$ & 11.5 (11.1 to 12.0$)$ & $12.2(11.7$ to 12.7$)$ & $12.7(12.2$ to 13.2$)$ & 12.7 (12.2 to 13.2$)$ \\
\hline $\mathrm{p}$ Value & 0.48 & 0.21 & 0.19 & 0.22 & 0.60 \\
\hline \multicolumn{6}{|c|}{ Co-morbidity, ${ }^{*} \mathrm{n}(\%)$} \\
\hline Overall & $559(60.0)$ & $649(63.3)$ & $475(57.3)$ & $519(56.8)$ & $560(56.8)$ \\
\hline Women & $428(59.8)$ & $516(64.7)$ & $361(56.5)$ & $394(54.6)$ & $427(56.3)$ \\
\hline Men & $131(60.9)$ & $133(58.3)$ & $114(60.0)$ & $125(64.8)$ & $133(58.3)$ \\
\hline $\mathrm{p}$ Value & 0.37 & 0.08 & 0.39 & 0.01 & 0.59 \\
\hline \multicolumn{6}{|c|}{ Seropositive, $†$ n (\%) } \\
\hline Overall & $426(45.8)$ & $473(46.1)$ & $381(46.0)$ & 445 (48.7) & $549(55.7)$ \\
\hline Women & $324(45.3)$ & $363(45.5)$ & $297(46.5)$ & $346(48.0)$ & 419 (55.3) \\
\hline Men & $102(47.4)$ & $110(48.2)$ & $84(44.2)$ & $99(51.3)$ & $130(57.0)$ \\
\hline$p$ Value & 0.57 & 0.49 & 0.56 & 0.52 & 0.75 \\
\hline
\end{tabular}

Overall improvement over the 15 -year period was statistically significant for MHAQ, SF-36 PCS, VAS (pain, PtGA and fatigue) and SF-6D (all $\mathrm{p}<0.001$, figure 1), but not for SF-36 MCS. Statistically significant improvement over 15 years was

\begin{tabular}{|c|c|c|c|c|c|}
\hline & $\begin{array}{l}1994 \\
(n=931)\end{array}$ & $\begin{array}{l}1996 \\
(n=1025)\end{array}$ & $\begin{array}{l}2001 \\
(n=829)\end{array}$ & $\begin{array}{l}2004 \\
(n=914)\end{array}$ & $\begin{array}{l}2009 \\
(n=986)\end{array}$ \\
\hline \multicolumn{6}{|c|}{ Glucocorticosteroids } \\
\hline Overall & $379(40.7)$ & $436(42.5)$ & $354(42.7)$ & $379(41.5)$ & 341 (34.6) \\
\hline Women & $293(40.9)$ & $340(42.7)$ & 267 (41.8) & 301 (41.7) & $265(35.0)$ \\
\hline Men & $86(40.0)$ & $96(42.1)$ & $87(45.8)$ & $78(40.4)$ & $76(33.3)$ \\
\hline \multicolumn{6}{|l|}{ sDMARD } \\
\hline Overall & 339 (36.4) & $405(39.5)$ & $401(48.4)$ & $495(54.2)$ & 587 (59.5) \\
\hline Women & $266(37.2)$ & 316 (39.6) & $312(48.8)$ & $391(54.2)$ & 448 (59.1) \\
\hline Men & $73(34.0)$ & $89(39.0)$ & $89(46.8)$ & 104 (53.9) & $139(61.0)$ \\
\hline \multicolumn{6}{|l|}{ bDMARD } \\
\hline Overall & NA & NA & $27(3.3)$ & $108(11.8)$ & $202(20.5)$ \\
\hline Women & NA & NA & $24(3.8)$ & $88(12.2)$ & $157(20.7)$ \\
\hline Men & NA & NA & $3(1.6)$ & $20(10.4)$ & $45(19.7)$ \\
\hline
\end{tabular}

All values: $n(\%)$. $p$ Values for difference between men and women at all time points were non-significant $(p>0.05)$.

bDMARD, biological disease modifying antirheumatic drug; sDMARD, synthetic

disease modifying antirheumatic drug; NA, not applicable. also observed for MHAQ, SF-36 PCS, VAS pain and VAS PtGA (both genders, all $\mathrm{p}<0.01$ ), VAS fatigue and SF-6D (women, both $\mathrm{p}<0.001$ ) and SF-6D (men, $\mathrm{p}=0.01$ ) (figure 2). The gender gap was reduced as indicated by decreasing differences between women and men over time (table 3, $\Delta$ females-males). For example, the gender difference in mean MHAQ score was reduced from 0.23 to 0.07 (table 3 ) and the gradually reduced distance between the 95\% CIs for men and women is clearly demonstrated in figure 2.

\section{DISCUSSION}

The present study in a representative RA population shows that health status continues to improve over 15 years (table 2 and figure 1). ${ }^{19}$ For the first time, we demonstrate a reduced gender gap over time in physical disability, pain, PtGA and utility (SF-6D) over a 15-year period in that women improved more than men (table 3 and figure 2). The use of antirheumatic medication was similar between genders. There was a generally marked increase in use of bDMARDs from 3.1\% in 2001 to $20.5 \%$ in 2009 and sDMARDs from $36.4 \%$ in 1994 to $59.5 \%$ in 2009 , documenting the impact of increased availability of medication and adherence to new treatment recommendations between 1994 and 2009.

Our patients present with manifestations of milder disease over the 15 years, extending similar results from previous studies with a shorter time frame. ${ }^{18} 19$ A German collaboration 
Table 3 Patient-reported outcome scores in the Oslo rheumatoid arthritis register from 1994 to 2009

\begin{tabular}{|c|c|c|c|c|c|}
\hline & $\begin{array}{l}1994 \\
(n=931)\end{array}$ & $\begin{array}{l}1996 \\
(n=1025)\end{array}$ & $\begin{array}{l}2001 \\
(n=829)\end{array}$ & $\begin{array}{l}2004 \\
(n=914)\end{array}$ & $\begin{array}{l}2009 \\
(n=986)\end{array}$ \\
\hline \multicolumn{6}{|l|}{ MHAQ (0-3) } \\
\hline Overall & 0.68 (0.64 to 0.72$)$ & $0.66(0.62$ to 0.69$)$ & $0.58(0.54$ to 0.62$)$ & 0.55 (0.51 to 0.58$)$ & $0.43(0.40$ to 0.46$)$ \\
\hline Women & 0.73 (0.69 to 0.78 ) & 0.70 (0.66 to 0.74$)$ & 0.61 (0.57 to 0.65$)$ & $0.56(0.53$ to 0.60$)$ & 0.44 (0.41 to 0.48$)$ \\
\hline Men & 0.50 (0.44 to 0.57$)$ & 0.51 (0.43 to 0.58 ) & 0.47 (0.40 to 0.54$)$ & 0.48 (0.41 to 0.55$)$ & 0.37 (0.32 to 0.43$)$ \\
\hline$\Delta$ Women-Men & $0.23(0.14$ to 0.32$)$ & $0.19(0.10$ to 0.28$)$ & $0.14(0.06$ to 0.23$)$ & $0.08(0.00$ to 0.16$)$ & 0.07 (0.01 to 0.14$)$ \\
\hline $\mathrm{p}$ Value & $<0.001$ & $<0.001$ & 0.001 & 0.05 & 0.03 \\
\hline \multicolumn{6}{|l|}{ SF-36 PCS (0-100) } \\
\hline Overall & 31.4 (30.7 to 32.2 ) & 32.0 (31.3 to 32.7 ) & 32.7 (31.9 to 33.5 ) & 33.7 (32.9 to 34.4 ) & 36.4 (35.7 to 37.2 ) \\
\hline Women & 30.4 (29.6 to 31.3$)$ & 31.1 (30.3 to 31.9) & 32.0 (31.1 to 32.9 ) & 33.0 (32.2 to 33.9$)$ & 36.0 (35.1 to 36.8 ) \\
\hline Men & 34.7 (33.0 to 36.4 ) & 35.1 (33.5 to 36.7 ) & 35.0 (33.3 to 36.6$)$ & 36.0 (34.3 to 37.7$)$ & 38.0 (36.4 to 39.5 ) \\
\hline$\Delta$ Women-men & $-4.3(-6.1$ to -2.4$)$ & $-4.0(-5.8$ to -2.2$)$ & $-3.0(14.8$ to -1.1$)$ & $-2.9(-4.8$ to -1.1$)$ & $-2.0(-3.8$ to -0.3$)$ \\
\hline $\mathrm{p}$ Value & $<0.001$ & $<0.001$ & 0.002 & 0.002 & 0.02 \\
\hline \multicolumn{6}{|l|}{ VAS PtGA (0-100) } \\
\hline Overall & 49.3 (47.8 to 50.9 ) & 44.9 (43.5 to 46.3$)$ & 39.8 (38.0 to 41.5$)$ & 38.2 (36.6 to 39.8 ) & 36.7 (35.2 to 38.3 ) \\
\hline Women & 50.6 (48.8 to 52.4$)$ & 46.2 (44.6 to 47.8 ) & 41.8 (39.8 to 43.8 ) & 39.4 (37.6 to 41.2 ) & 37.3 (35.6 to 39.1 ) \\
\hline Men & 45.2 (41.8 to 48.6 ) & 40.6 (37.6 to 43.6 ) & 33.0 (29.5 to 36.4$)$ & 33.8 (30.4 to 37.2 ) & 34.6 (31.3 to 37.9 ) \\
\hline$\Delta$ Women-men & 5.4 (1.7 to 9.1$)$ & $5.6(2.2$ to 9.0$)$ & 8.9 (4.7 to 13.0$)$ & 5.6 (1.6 to 9.5$)$ & $2.7(-1.0$ to 6.4$)$ \\
\hline $\mathrm{p}$ Value & 0.004 & 0.001 & $<0.001$ & 0.01 & 0.15 \\
\hline \multicolumn{6}{|l|}{ VAS pain $(0-100)$} \\
\hline Overall & 46.0 (44.4 to 47.5$)$ & 37.7 (36.2 to 39.1$)$ & 35.8 (34.1 to 37.5 ) & 34.5 (33.0 to 36.1 ) & 34.0 (32.5 to 35.5$)$ \\
\hline Women & 47.4 (45.7 to 49.1$)$ & 39.5 (37.8 to 41.1$)$ & 37.8 (35.9 to 39.8 ) & 35.6 (33.8 to 37.3 ) & 34.5 (32.8 to 36.3 ) \\
\hline Men & 41.1 (37.7 to 44.4 ) & 31.4 (28.2 to 34.5$)$ & 29.0 (25.8 to 32.3$)$ & 30.7 (27.4 to 34.1 ) & 32.3 (29.0 to 35.6 ) \\
\hline$\Delta$ Women-men & $6.3(2.7$ to 10.0$)$ & 8.1 (4.6 to 11.6 ) & 8.8 (4.8 to 12.7 ) & 4.8 (1.0 to 8.7$)$ & $2.3(-1.4$ to 5.9$)$ \\
\hline $\mathrm{p}$ Value & 0.001 & $<0.001$ & $<0.001$ & 0.01 & 0.22 \\
\hline \multicolumn{6}{|l|}{ VAS fatigue $(0-100)$} \\
\hline Overall & $50.0(48.2$ to 51.8$)$ & 44.0 (42.3 to 45.8$)$ & 46.9 (44.9 to 48.9$)$ & 46.1 (44.2 to 48.1$)$ & 44.1 (42.3 to 45.9$)$ \\
\hline Women & $52.4(50.3$ to 54.4$)$ & 46.3 (44.3 to 48.4$)$ & 50.0 (47.7 to 52.3$)$ & 48.4 (46.2 to 50.6$)$ & 45.3 (43.2 to 47.3 ) \\
\hline Men & 41.9 (38.0 to 45.8$)$ & 35.9 (32.2 to 39.6$)$ & 36.5 (32.8 to 40.3$)$ & 37.7 (33.6 to 41.7 ) & 40.1 (36.4 to 43.8 ) \\
\hline$\Delta$ Women-men & $10.5(6.2$ to 14.7$)$ & $10.4(6.2$ to 14.7$)$ & 13.4 (8.8 to 18.1$)$ & 10.7 (6.1 to 15.3$)$ & 5.2 (0.9 to 9.5$)$ \\
\hline $\mathrm{p}$ Value & $<0.001$ & $<0.001$ & $<0.001$ & $<0.001$ & 0.02 \\
\hline \multicolumn{6}{|l|}{ SF-6D (0.29-1) } \\
\hline Overall & 0.616 (0.607 to 0.625$)$ & 0.617 (0.608 to 0.625$)$ & $0.639(0.629$ to 0.649$)$ & 0.647 (0.638 to 0.656$)$ & 0.672 (0.663 to 0.681$)$ \\
\hline Women & 0.607 (0.597 to 0.617 ) & 0.609 (0.599 to 0.618$)$ & $0.632(0.621$ to 0.644$)$ & 0.641 (0.631 to 0.651$)$ & 0.669 (0.658 to 0.679$)$ \\
\hline Men & 0.645 (0.625 to 0.665$)$ & 0.645 (0.626 to 0.663$)$ & 0.660 (0.639 to 0.682$)$ & 0.672 (0.652 to 0.691$)$ & $0.686(0.665$ to 0.706$)$ \\
\hline$\Delta$ Women-men & $-0.038(-0.060$ to -0.017$)$ & $-0.036(-0.056$ to -0.016$)$ & $-0.028(-0.052$ to -0.005$)$ & $-0.031(-0.053$ to -0.009$)$ & $-0.017(-0.039$ to 0.005$)$ \\
\hline$p$ Value & 0.001 & 0.001 & 0.02 & 0.005 & 0.12 \\
\hline \multicolumn{6}{|l|}{ SF-36 MCS (0-100) } \\
\hline Overall & 46.3 (45.5 to 47.2 ) & 45.3 (44.5 to 46.1$)$ & $47.0(46.2$ to 47.9$)$ & 47.5 (46.7 to 48.3$)$ & 47.3 (46.6 to 48.1 ) \\
\hline Women & 45.8 (44.8 to 46.8$)$ & $45.0(44.2$ to 45.9$)$ & 46.8 (45.8 to 47.7$)$ & 47.2 (46.2 to 48.1$)$ & $47.2(46.4$ to 48.0$)$ \\
\hline Men & 48.1 (46.4 to 49.8 ) & 46.2 (44.5 to 47.9$)$ & 47.8 (46.2 to 49.5$)$ & 48.7 (47.0 to 50.4 ) & 47.7 (46.1 to 49.3 ) \\
\hline$\Delta$ Women-men & $-2.4(-4.4$ to -0.4$)$ & $-1.1(-3.0$ to 0.7$)$ & $-1.1(-3.0$ to 0.9$)$ & $-1.6(-3.6$ to 0.41$)$ & $-0.5(-2.3$ to 1.3$)$ \\
\hline$p$ Value & 0.02 & 0.22 & 0.29 & 0.12 & 0.57 \\
\hline
\end{tabular}

study from 1997-2007 demonstrated lower disease activity, less painful and swollen joints and reduced sick-leave in RA patients with improved RA treatment. ${ }^{30}$ Krishnan $e t a l^{31}$ reported lower disability after the introduction of sDMARDs and further improvement after bDMARDs introduction. Our approach was to follow PROs in an RA population in Oslo, Norway, with repeated cross-sectional measurements. In contrast to our observation of improving health status during recent years in an RA register, patients with RA would generally experience deteriorating physical function (HAQ) of $0.01-0.03$ units per year. ${ }^{11-13}$ A Finnish study observed similar progression rates for HAQ in the general population and RA patients $<70$ years old from $2000-2005 .^{11}$

A study from the Danish DANBIO register reported a better response among men than women to bDMARDs in early, but not in established RA. ${ }^{5}$ Our observation of women reporting more somatic symptoms than men in 1994 is consistent with results from other studies. ${ }^{3} 3233$ However, comparing these populations directly may not be feasible due to varying inclusion/exclusion criteria, follow-up schedules, sample sizes and measured PROs. Björk et al used longitudinal data from Sweden and the USA to compare disability, ${ }^{34}$ and suggested that 

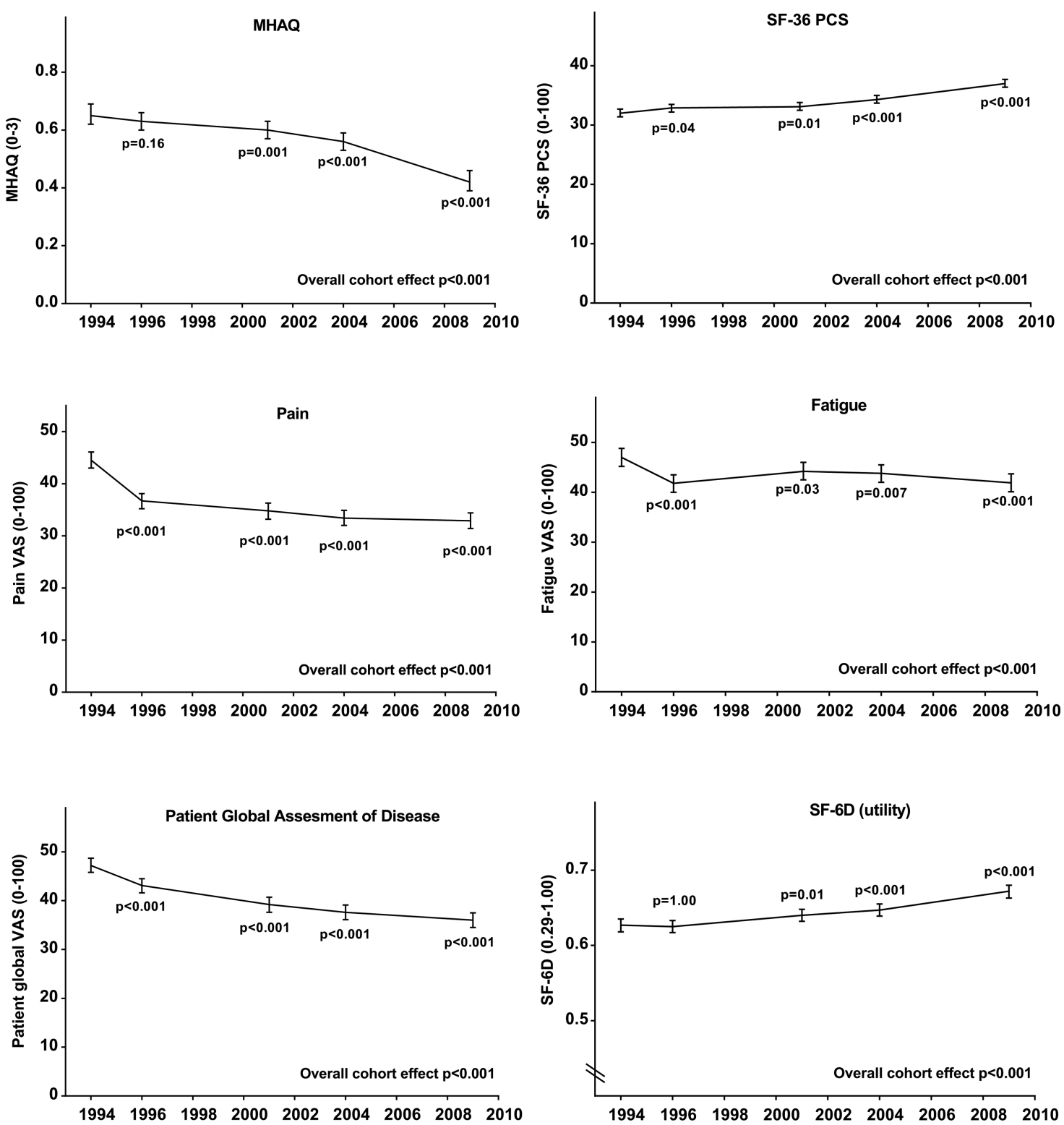

Figure 1 Overall trends in patient reported outcomes from 1994 to 2009 in the Oslo rheumatoid arthritis register. Means with 95\% Cls calculated by a mixed model approach; adjusted for age $=60.0$ years, disease duration=13.7 years and gender. $p$ Values compared to 1994 with Bonferroni adjustment for multiple comparisons. MHAQ, Modified Health Assessment Questionnaire ( $0-3,0$ best); SF-36, Short Form 36 questionnaire (0-100, 100 best); SF-36 PCS, SF-36 physical component summary; VAS, visual analogue scale (0-100, 100 best); SF-6D, SF-36 utility (0.29-1.00, 1.00 best).

disability reporting may be influenced by the psychosocial and cultural context. There has also been some concerns whether the observed gender differences in RA may originate from the disease activity measures rather than actual gender differences in RA disease activity. ${ }^{32}$ In the present study we repeatedly used the same disease activity measures over 15 years and the women reported significantly more improvement than men. This finding suggests that the observed gender difference in 1994 and indications of a closing gender gap are real, and not related to methods inherent to assessment of health status.

An important and clinically relevant finding of our study is the continuously improved physical function, especially for women (mean change MHAQ from 1994 to 2009: overall -0.25 , women -0.29 , and men -0.13). A difference of between 0.22 and 0.25 in HAQ and MHAQ is suggested as the minimally clinical important difference (MCID). ${ }^{35}$ Pope et $a l^{37}$ suggest MCID for HAQ in RA clinical practice may be even smaller $(-0.20)$ than in randomised controlled trials. Translating this threshold into simple language, our representative RA population has experienced a clinically important improvement of the physical burden from RA over the 15 years. This is an important message and can be considered as a reward for improved treatment strategies, that is, earlier diagnosis and treatment with sDMARDs, access to new therapies and possibly better informed patients with improved treatment adherence during the last 15 years.

The level of pain was reduced over the 15 -year study period in the range of about $10 \mathrm{~mm}$ on a $100 \mathrm{~mm}$ VAS scale: $-12 \mathrm{~mm}$ overall, $-12.9 \mathrm{~mm}$ for women and $-8.8 \mathrm{~mm}$ for men. VAS pain is the best evaluated pain measure in $\mathrm{RA},{ }^{38}$ and Wolfe and Michaud reported a minimally clinical important change for VAS pain $(0-10)$ in RA of $0.5-1.1,{ }^{39}$ corresponding to $5-11 \mathrm{~mm}$ on a $100 \mathrm{~mm}$ VAS. Thus, the ORAR patients also experienced a clinically important improvement in pain on a group level, 

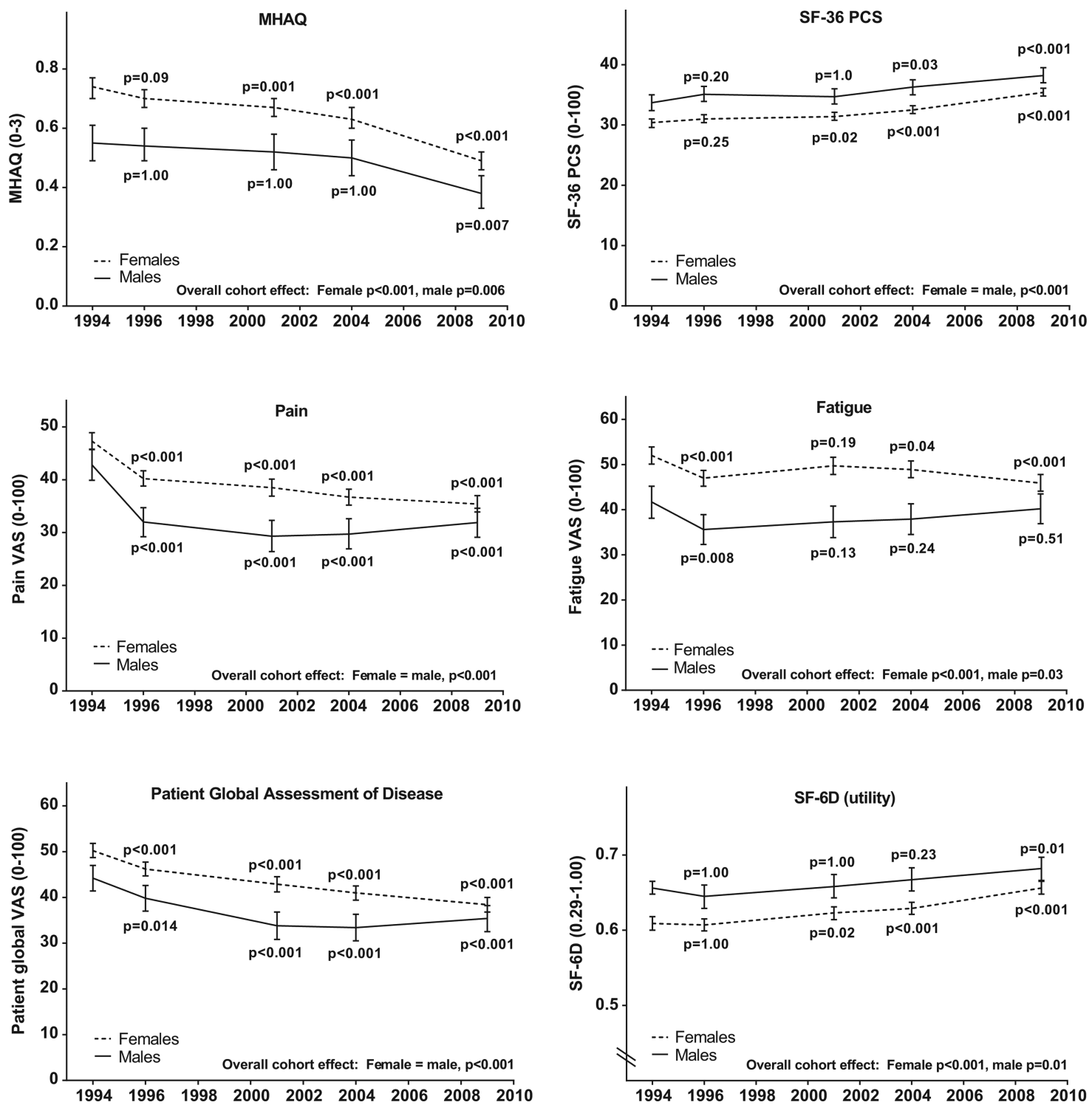

Figure 2 Trends in patient reported outcomes for men and women from 1994 to 2009 in the Oslo rheumatoid arthritis register (ORAR). Means with $95 \%$ Cls calculated by a mixed model approach; adjusted for age $=60.0$ years, disease duration $=13.7$ years and gender. $p$ Values compared to 1994 with Bonferroni adjustment for multiple comparisons. MHAQ, Modified Health Assessment Questionnaire (0-3, 0 best); SF-36, Short Form 36 questionnaire (0-100, 100 best); SF-36 PCS, SF-36 physical component summary; VAS, visual analogue scale (0-100, 100 best); SF-6D, SF-36 utility (0.29-1.00, 1.00 best).

which is particularly important since pain is the most important symptom from a patient perspective. ${ }^{40} 41$ PtGA also improved statistically significantly in our population. A widely accepted definition MCID in PtGA would be difficult to validate across populations as a number of factors (eg, ethnicity, education, initial disease activity etc) could influence this outcome measure.

Utility (SF-6D, a measure of disease burden combining life quality and duration) improved 0.056 over the 15 years and more for women than men (0.062 and 0.041, respectively). Walters and Brazier reported that a mean minimally important difference for SF-6D is $0.041,{ }^{27}$ indicating clinically important improvements in utility during our time frame of 15 years. Our results indicate that 100 RA patients gained 5.6 quality adjusted life years (QALYs), that is, overall, 100 RA patients gained an additional 5.6 years of 'perfect health' in 2009 vs 1994. This information of improved health may be relevant for payers and decision makers who have to make priorities about costs across different disease areas.
Increased use of sDMARDs and bDMARDs coincides with the improved health status, but our study was not designed to show a causal relationship between medication and improved PROs. Uncertainty about causality is raised by the finding that women improved more than men without differences in use of medication (sDMARDs and bDMARDs). Another study found men to respond better to bDMARDs than women in early RA, suggesting that other, ${ }^{5}$ yet unidentified factors, may influence PROs.

There may be different mechanisms underlying the reduced gender gap observed. We did not find any age difference between genders, but women had longer disease duration than men. Considering the natural development of RA, a higher impact of disease would be expected in later stages of RA. Onset of RA is on average earlier in women than men. ${ }^{6}$ Thus, at the same age women would be expected to have longer disease duration than men and therefore report a higher accrued disease impact. Referral delay for women versus men has been 
reported, ${ }^{42}$ but ORAR does not record time from symptom onset to diagnosis and/or treatment initiation.

A strength of our study is that the RA population has been validated and found to be representative of all patients with RA in Oslo under the age of 80 years. $^{2}$ Further, data were collected at five time points over 15 years and applying different instruments measuring the same health dimensions. The consistency of the findings across instruments for the same dimensions increases the validity and robustness of the reported findings. Our patient population is unselected and includes patients regardless of disease activity or whether patients met for routine control appointments. Finally, this repeated cross-sectional study provides an opportunity to also study the gender specific development in health status during a period with major improvement in treatment strategies and access to new and more targeted therapies.

The study also has some limitations. We collected only PROs and did not have the opportunity to compare disease activity and study joint damage over time. However, in a previous study with incidence cohorts from ORAR during the first 10 years, disease activity measured by DAS28 improved over time. ${ }^{43}$ Further, self-reported information about medication may be subject to bias. We manually checked a random 5\% sample of the patients' records for prescribed versus reported antirheumatic medication and found good agreement. Collecting data in one geographical area provides good internal validity but at the cost of external validity due to possible differences in the cultural context. ${ }^{34}$ Finally, life conditions and healthcare settings continuously change and some unmeasured factors may have led to changes in observed health status.

In conclusion, we demonstrated improvement in crude PROs for disability, physical function, pain, global disease activity and fatigue from 1994 to almost all subsequent time points. Longitudinal analyses demonstrated statistically significant improvement for all PROs except SF-36 MCS from 1994 onwards, coinciding with increased use of DMARDs (synthetic and biological). Importantly, women improved more than men and the statistically significant gender gap observed in 1994 was considerably diminished at the final assessment in 2009.

Acknowledgements The authors would like to thank all patients for contributing with data to the study.

Contributors All authors have participated in this work and participated in the drafting of the manuscript. CA and ICO performed the statistical analyses.

Funding The study was supported by a grant from the Norwegian South East Health Authorities.

\section{Competing interests None.}

Ethics approval The study was approved by the regional ethics committee.

Provenance and peer review Not commissioned; externally peer reviewed.

\section{REFERENCES}

1 Symmons DP, Barrett EM, Bankhead CR, et al. The incidence of rheumatoid arthritis in the United Kingdom: results from the Norfolk Arthritis Register. $\mathrm{Br} J$ Rheumatol 1994:33:735-9.

2 Kvien TK, Glennås A, Knudsrød OG, et al. The prevalence and severity of rheumatoid arthritis in Oslo. Results from a county register and a population survey. Scand J Rheumatol 1997;26:412-18.

3 Ahlmén $M$, Svensson B, Albertsson $\mathrm{K}$, et al. Influence of gender on assessments of disease activity and function in early rheumatoid arthritis in relation to radiographic joint damage. Ann Rheum Dis 2010;69:230-3.

4 Forslind K, Hafström I, Ahlmén $M$, et al. Sex: a major predictor of remission in early rheumatoid arthritis? Ann Rheum Dis 2007;66:46-52.

5 Jawaheer D, Olsen J, Hetland ML. Sex differences in response to anti-tumor necrosis factor therapy in early and established rheumatoid arthritis-results from the DANBIO registry. J Rheumatol 2012;39:46-53.

6 Kvien TK, Uhlig T, Ødegård $S$, et al. Epidemiological aspects of rheumatoid arthritis. The sex ratio. Ann N Y Acad Sci 2006;1069:212-22.
7 Katz PP, Criswell LA. Differences in symptom reports between men and women with rheumatoid arthritis. Arthritis Care Res 1996:9:441-8.

8 Barnabe C, Bessette L, Flanagan C, et al. Sex differences in pain scores and localization in inflammatory arthritis: a systematic review and metaanalysis. J Rheumatol 2012;39:1221-30

9 Jawaheer D, Maranian P, Park G, et al. Disease progression and treatment responses in a prospective DMARD-naive seropositive early rheumatoid arthritis cohort: does gender matter? J Rheumatol 2010:37:2475-85.

10 Gossec L, Baro-Riba J, Bozonnat M-C, et al. Influence of sex on disease severity in patients with rheumatoid arthritis. J Rheumatol 2005:32:1448-51.

11 Sokka $T$, Kautiainen $\mathrm{H}$, Hannonen $\mathrm{P}$, et al. Changes in health assessment questionnaire disability scores over five years in patients with rheumatoid arthritis compared with the general population. Arthritis Rheum 2006;54 3113-18.

12 Gardiner PV, Sykes HR, Hassey GA, et al. An evaluation of the health assessment questionnaire in long-term longitudinal follow-up of disability in rheumatoid arthritis. Br J Rheumatol 1993:32:724-8.

13 Ward MM, Leigh JP, Fries JF, et al. Progression of functional disability in patients with rheumatoid arthritis: associations with rheumatology subspeciality care. Arch Intern Med 1993;153:2229-37

14 Krishnan E, Sokka T, Häkkinen A, et al. Normative values for the health assessment questionnaire disability index. Benchmarking disability in the general population. Arthritis Rheum 2004;50:953-60.

15 Singh JA, Furst DE, Bharat A, et al. 2012 update of the 2008 American College of Rheumatology recommendations for the use of disease-modifying antirheumatic drugs and biologic agents in the treatment of rheumatoid arthritis. Arthritis Care Res (Hoboken) 2012;64:625-39.

16 Smolen JS, Landewé $R$, Breedveld $F$, et al. EULAR recommendations for the management of rheumatoid arthritis with synthetic and biological disease-modifying antirheumatic drugs. Ann Rheum Dis 2010;69:964-75.

17 Krishnan E, Fries JF. Reduction in long-term functional disability in rheumatoid arthritis from 1977 to 1998: a longitudinal study of 3035 patients. Am J Med 2003:115:371-6

18 Welsing PM, Fransen J, van Riel PL. Is the disease course of rheumatoid arthritis becoming milder? Time trends since 1985 in an inception cohort of early rheumatoid arthritis. Arthritis Rheum 2005;52:2616-24.

19 Uhlig T, Heiberg T, Mowinckel $P$, et al. Rheumatoid arthritis is milder in the new millennium: health status in RA patients 1994-2004. Ann Rheum Dis 2008:67:1710-15.

20 Kvien TK, Uhlig T. The Oslo experience with arthritis registries. Clin Exp Rhematol 2003:31:315-24.

21 Arnett FC, Edworthy SM, Bloch DA, et al. The American Rheumatism Association 1987 revised criteria for the classification of rheumatoid arthritis. Arthritis Rheum 1988:31:315-24.

22 Pincus T, Summey JA, Soraci SA Jr, et al. Assessment of patient satisfaction in activities of daily living using a modified Stanford Health Assessment Questionnaire. Arthritis Rheum 1983;26:1346-53.

23 Ware JE Jr, Sherbourne CD. The MOS 36-item short-form health survey (SF-36). I. Conceptual framework and item selection. Med Care 1992;30: 473-83.

24 Kvien TK, Kaasa S, Smedstad LM. Performance of the Norwegian SF-36 Health Survey in patients with rheumatoid arthritis. II. A comparison of the SF-36 with disease-specific measures. J Clin Epidemiol 1998:51:1077-86.

25 Ekdahl C, Eberhardt K, Andersson SI, et al. Assessing disability in patients with rheumatoid arthritis. Use of a Swedish version of the Stanford Health Assessment Questionnaire. Scand J Rheumatol 1988;17:263-71.

26 Brazier J, Roberts J, Deverill M. The estimation of a preference-based measure of health from the SF-36. J Health Econ 2002;21:271-92.

27 Walters SJ, Brazier JE. Comparison of the minimally important difference for two health state utility measures: EQ-5D and SF-6D. Qual Life Res 2005;14: 1523-32.

28 Meenan RF, Mason JG, Anderson JJ, et al. AIMS2. The content and properties of a revised and expanded Arthritis Impact Measurement Scales Health Status Questionnaire. Arthritis Rheum 1992;35:1-10.

29 Raza K, Saber TP, Kvien TK, et al. Timing the therapeutic window of opportunity in early rheumatoid arthritis: proposal for definitions of disease duration in clinical trials. Ann Rheum Dis 2012;71:1921-3.

30 Ziegler $\mathrm{S}$, Huscher D, Karberg K, et al. Trends in treatment and outcomes of rheumatoid arthritis in Germany 1997-2007: results from the National Database of the German Collaborative Arthritis Centres. Ann Rheum Dis 2011;69:1803-8.

31 Krishnan $E$, Lingala $B$, Bruce $B$, et al. Disability in rheumatoid arthritis in the era of biological treatments. Ann Rheum Dis 2012;71:213-18.

32 Sokka T, Toloza S, Cutolo M, et al. Women, men, and rheumatoid arthritis: analyse of disease activity, disease characteristics, and treatments in the QUEST-RA Study. Arthritis Res Ther 2009;11:R7.

33 Barsky AJ, Peekna HM, Borus JF. Somatic Symptom Reporting in Women and Men. J Gen Intern Med 2001;16:266-75. 
34 Björk M, Trupin L, Thyberg I, et al. Differences in activity limitation, pain intensity, and global health in pts with rheumatoid arthritis in Sweden and the USA: a 5-year follow-up. Scand J Rheumatol 2011:40:428-32.

35 Kosinski M, Zhao SZ, Dedhiya $S$, et al. Determining minimally important changes in generic and disease-specific health-related quality of life questionnaires in clinical trials of rheumatoid arthritis. Arthritis Rheum 2000;43:1478-87.

36 Wolfe F, Pincus T. Listening to the patient. A practical guide to self-report questionnaires in clinical care. Arthritis Rheum 1999:42:1797-808.

37 Pope JE, Khanna D, Norrie D, et al. The minimally important difference for the health assessment questionnaire in rheumatoid arthritis clinical practice is smaller than in randomized controlled trials. J Rheumatol 2009:36:254-9.

38 Engelbrecht M, Tarner IH, van der Heijde D, et al. Measuring pain and efficacy of pain treatment in inflammatory arthritis: a systematic literature review. J Rheumatol supp/ 2012;90:3-10.
39 Wolfe F, Michaud K. Assessment of pain in rheumatoid arthritis: minimal clinically significant difference, predictors, and the effect of anti-tumor necrosis factor therapy. J Rheumatol 2007;34:1674-83.

40 Heiberg T, Kvien TK. Preferences for improved health examined in 1024 patients with rheumatoid arthritis: pain has highest priority. Arthritis Rheum 2002:47:391-7.

41 Heiberg T, Austad C, Kvien TK, et al. Performance of the rheumatoid arthritis impact of disease (RAID) score in relation to other patient-reported outcomes in a register of patients with rheumatoid arthritis. Ann Rheum Dis 2011;70:1080-2.

42 Palm Ø, Purinszky E. Women with early rheumatoid arthritis are referred later than men. Ann Rheum Dis 2005;64:1227-8.

43 Ødegård S, Kvien TK, Uhlig T. Incidence of clinically important 10-year health status and disease activity levels in population-based cohorts with rheumatoid arthritis. J Rheumatol 2008;35:54-60. 